\title{
Direito à educação, formação do adolescente e adoecimento docente no Estado capitalista
}

\author{
Herculano Ricardo Campos \\ Universidade Federal do Rio Grande do Norte \\ Záira Fátima de Rezende Gonzalez Leal \\ Marilda Gonçalves Dias Facci \\ Universidade Estadual de Maringá
}

\section{Resumo}

A educação, não obstante ser considerada direito humano universal, e contemplada na legislação nacional e internacional, tem sua efetivação enquanto política pública marcada por significativa distância entre o direito instituído e o direito efetivado, expressão das contradições que caracterizam o Estado capitalista. Tomando essa assertiva como ponto de partida e valendo-se do referencial do materialismo histórico-dialético, como formulado por Marx e Engels, e da Psicologia Histórico-Cultural, estruturada a partir de Vygotsky, Luria e Leontiev, o presente artigo visa problematizar a distância entre o que prevê a legislação e o que é efetivamente implementado na sociedade, privilegiando a reflexão sobre os efeitos de tal situação na vida de alunos/adolescentes e professores. Revela-se a constituição e a feição de classe que marcam o Estado e sua íntima relação com as características que assumem as políticas públicas; a falta de preparo das escolas para efetivar uma formação coerente com o desenvolvimento de alunos adolescentes; e o adoecimento dos professores em face da impotência, e da cobrança, para lidar com questões para as quais não se sentem preparados.

Palavras-chave: Direito à educação. Formação do adolescente. Adoecimento docente.

\section{Right to education, adolescent education and teaching illness in the capitalist state}

\section{Abstract}

Education, despite be considered universal human right and thus be covered by national and international law, has its effectiveness as a public policy marked by significant distance between the right and set up the right effected, expression of the contradictions that mark the capitalist state. Taking this statement as a starting point, and supported in the framework of the historical and dialectical materialism, as formulated by 
Direito à Educação, formação do adolescente e adoecimento docente no Estado capitalista

Marx and Engels, and Historical-Cultural Psychology, structured from Vygotsky, Luria and Leontiev, this article aims to problematize the distance between providing for the legislation and what is actually implemented in the society, focusing reflection on the effects of such a situation in the lives of students/adolescents and teachers. It exposes the constitution and class feature that mark the state and its close relationship with the characteristics that assume public policies; the lack of preparation of schools to carry out a coherent training with the development of adolescent students; and the illness of teachers in the face of powerlessness, and the accountability, to deal with questions to which they do not feel prepared.

Keywords: Right to education. Adolescent education. Teaching illness.

\section{Derecho a la educación, la educación de los adolescentes y la enfer- medad de los docentes en el Estado capitalista}

\section{Resumen}

Educación, a pesar de derecho humano universal y por lo tanto estar cubiert por la legislación nacional e internacional, tiene su eficacia como política pública marcada por la distancia significativa entre el derecho establecido y el derecho efectuado, expresión de las contradicciones que marcan el estado capitalista. Tomando esta afirmación como un punto de partida, y en base a la referencia del materialismo histórico y dialéctico, tal como fue formulada por Marx y Engels, y Psicología Histórico-Cultural, estructurado a partir de Vygotsky, Luria y Leontiev, este artículo pretende problematizar la distancia entre la legislación y entre lo que realmente es implantado en la sociedad, focando en reflexión sobre los efectos de una situación tal en la vida de los estudiantes/ adolescentes y maestros. Se revela la constitución e la fisonomía de clase que marcan el estado y su estrecha relación con las características que asumen las políticas públicas; la falta de preparación de las escuelas para llevar a cabo una formación coherente con el desarrollo de los estudiantes adolescentes; y la enfermedad de los maestros ante la impotencia, y la cobranza, para hacer frente a asuntos a los que no se sienten preparados.

Palabras llave: Derecho a la educación. La formación del adolescente. Enfermedad de los docentes. 
Herculano Ricardo Campos | Záira Fátima de Rezende Gonzalez Leal | Marilda Gonçalves Dias Facci 드

\section{Introdução}

Já constitui lugar comum as referências ao papel fundamental da educação com vistas à conquista da cidadania e ao desenvolvimento das nações. Vale ressaltar que essa compreensão tácita generalizada da educação, que é um direito subjetivo e universal, vem sendo construída, historicamente, na esteira do projeto moderno de sociedade, constituindo aspecto específico da legislação - de âmbito nacional e internacional - notadamente desde a Revolução Francesa, em 1789. Embora seja precedida, temporalmente, pela Declaração de direitos do bom povo de Virgínia, de 1776, e, de certo, modo ecoe seu conteúdo, a Declaração dos Direitos do Homem e do Cidadão, concebida no auge do conflito francês, merece destaque pela dimensão histórica que teve esse evento, norteando significativamente a configuração do modelo de sociedade atualmente ainda em vigor - particularmente no Ocidente. Essa perspectiva civilizatória, acentuada pelo movimento iluminista que se consolida após e em decorrência da Revolução, é marcada pelo fortalecimento dos valores liberais burgueses e pelo capitalismo como modo de produção.

Responsável por disseminar os ideais universais da igualdade, da fraternidade e da liberdade, como libelo contrário ao absolutismo, até então vigente, a Declaração vem a ser absorvida pela Convenção Nacional Francesa de 1793. Consta, nela, no seu art. 22, que "A instrução é a necessidade de todos. A sociedade deve favorecer com todo o seu poder o progresso da inteligência pública e colocar a instrução ao alcance de todos os cidadãos" (FRANCCA, 1789). Curiosamente, da mesma forma que o fim do conflito francês resultou no entendimento da educação como "necessidade de todos" pela Convenção que inaugurou a república francesa, a Declaração Universal dos Direitos do Homem, proclamada pela Organização das Nações Unidas (ONU) em 1948, após o término da Segunda Guerra Mundial, vem reiterar o papel central da educação, desta feita, entendida como "direito de todos", direito humano fundamental.

No Brasil, certos aspectos do direito à educação são tratados já na Constituição Imperial de 1824, nos incisos 32 e 33 do artigo 171. O primeiro trata da garantia da "instrução primária a todos os cidadãos", e o outro afirma o compromisso institucional com "colégios e universidades" (BRASIL, 1824). Posteriormente, a Constituição de 1934, no artigo 149, define a Educação como direito de todos, a ser ministrada pela família e pelos "Poderes Públicos" 
Direito à Educação, formação do adolescente e adoecimento docente no Estado capitalista

(BRASIL, 1934), e a Carta de 1946, no seu artigo 166, define a Educação como direito de todos, "e será dada no lar e na escola" (BRASIL, 1946). Na Constituição atual, de 1988, consta, no Artigo 205, que a "Educação, direito de todos e dever do Estado e da família, será promovida e incentivada com a colaboração da sociedade, visando ao pleno desenvolvimento da pessoa, seu preparo para o exercício da cidadania e sua qualificação para o trabalho" (BRASIL, 1988).

Em que pese o direito à educação, um direito universal, garantido, constitucionalmente, proclamado no âmbito social, nas políticas públicas, e, ainda, considerando que o Brasil é signatário de diversos tratados internacionais que contemplam a educação como direito, ainda hoje se convive com sérios problemas nessa área, a exemplo do elevado índice de fracasso escolar, ou seja, de estudantes que abandonam a escola ou que sofrem sucessivas reprovações. Quando se analisam os dados do Índice de Desenvolvimento Educacional - Ideb - referente ao ano de 2013, constata-se que, nos anos iniciais do Ensino Fundamental, o índice aferido foi de 5,2; nos anos finais, de 4,2; e no Ensino Médio, de 3,7. Tendo em vista que o índice máximo é 10,0, fica evidente o quanto os alunos ainda apresentam dificuldades no processo 208 de escolarização, notadamente, em níveis mais avançados de ensino (BRASIL, 20151 .

No trabalho com as escolas, observam-se crianças da primeira fase do Ensino Fundamental que passam para o bo ano, muitas vezes, sem domínio dos rudimentos da escrita e da leitura; adolescentes que se ressentem e apresentam comportamentos de indisciplina e violência porque não estão conseguindo aprender e demonstrar suas potencialidades; estudantes que chegam ao Ensino Médio sem domínio das quatro operações básicas da matemática, com apropriação precária da língua portuguesa; essas dificuldades vão se arrastando para os anos posteriores, contribuindo, evidentemente, para a exclusão da escola. Nesse mesmo contexto, também se observa um número cada vez mais crescente de professores adoecendo, deixando de exercer seu papel diretamente no ensino dos alunos e sendo readaptados no contexto escolar, devido a problemas orgânicos e psíquicos decorrentes de insuficientes e inadequadas condições de trabalho.

Considerando os pontos arrolados, o presente artigo visa problematizar a contradição entre direitos instituídos e sua efetivação, tomando por foco a educação enquanto direito humano universal e privilegiando a reflexão sobre 
os efeitos de tal situação na vida de alunos/adolescentes e professores. Parte-se da apresentação dos elementos de caráter teórico-geral, responsáveis pela feição que assume na prática o direito à educação, ressaltando, nessa análise, as características do Estado, sua função social e sua relação com a implementação de políticas públicas, consideradas, de fato, de direitos. Assim, para mostrar o efeito dessa contradição em relação aos alunos/adolescentes, que tem levado à sua culpabilização e exclusão da escola, delineiam-se algumas das principais características que conformam a adolescência, sob o ponto de vista da Psicologia Histórico-Cultural, apontando a limitação das atuais práticas pedagógicas visando contribuir com conteúdos significativos, contemplando, assim, as potencialidades dos adolescentes em face do seu desenvolvimento. Ademais, constata-se que, sob o foco da Psicologia Histórico-Cultural, as inadequadas condições de trabalho e a crescente desconsideração da função social da educação, aliadas à necessidade de dar conta de inúmeras novas demandas apresentadas pelos estudantes, sem que para isso tenham sido adequadamente formados, têm levado professores à perda do sentido da sua profissão, consequentemente adoecendo física e psiquicamente e chegando a abandonar a sala de aula.

\section{Estado, educação e direito}

No projeto civilizatório que tem como marco inicial a Revolução Francesa, no século XVIII, e que encontra seu apogeu na consolidação do modo de produção capitalista, no final do século XIX, merece destaque o desenvolvimento da noção de 'direitos humanos', que, desde a Declaração Universal de Direitos Humanos, de 1948, são definidos como "[...] universais, indivisíveis, interdependentes entre si e destinados a garantir a dignidade humana" (GRACIANO, 2005, p. 23). Consta da Plataforma DhESCA Brasile Ação Educativa que,

Os direitos humanos foram construídos com base na ideia de dignidade da pessoa humana, ou seja, de que todo ser humano, independentemente de qualquer condição pessoal, deve ser igualmente reconhecido e respeitado, não podendo ser tratado como instrumento de poucos, mas sim como fim de toda organização social e política. [...] $\bigcirc$ reconhecimento internacional dos direitos humanos representou, assim, um passo histórico decisivo. Hoje 
Direito à Educação, formação do adolescente e adoecimento docente no Estado capitalista

muitos desses direitos estão previstos em documentos internacionais assinados por centenas de países e foram criados órgãos específicos para acompanhar sua implementação ao redor do mundo (PLATAFORMA DHESCA BRASIL, 2003, p. 14).

Não obstante os direitos humanos efetivamente constituírem uma expressão do parâmetro de sociabilidade pretendido com a emergência do Estado moderno - ou de direito -, árduas são as lutas travadas no seio da sociedade, em diferentes contextos e tempos históricos, para fazer com que o direito não esteja presente apenas na letra da lei, mas também que constitua um efetivo instrumento de garantia da dignidade humana. No estudo em que discorre sobre a legislação internacional com vistas à efetivação dos direitos humanos, notadamente da educação, por um lado, Graciano (2005) revela o avanço dos instrumentos legais de caráter internacional e o deslocamento, do âmbito local para o internacional, da responsabilização do Estado ante a concretização do direito. E, por outro lado, também revela que, a despeito da excelência e amplitude da legislação, "[...] a inscrição em normas é mais um instrumento de luta política pela conquista do direito do que propriamente sua garantia" (GRACIANO, 2005, p. 27).

210 A compreensão das razões por que tais lutas têm sido, e continuam se fazendo necessárias, requer clareza a respeito da contradição estrutural que caracteriza o Estado desde sua emergência, já nas formações sociais que sucederam as sociedades primitivas, e que nos alcança na forma atual do Estado de direito, também chamado de Estado burguês. Para contribuir com esse esclarecimento, efetua-se aqui uma interlocução com o texto de Florenzano (2007), sobre o Estado moderno, no qual realça os benefícios para a civilização dessa forma moderna de organização política da sociedade.

Inicialmente, o autor formula uma crítica a Marx e Engels, que, segundo ele, teriam sido levados por uma "visão negativa do poder instituído" e assim subestimado as diferentes "formas do Estado" identificadas no século XVIII - após o feudalismo -, entre as quais o "Estado constitucional ou de direito" (FLORENZANO, 2007, p. 13). A crítica, entendida como uma ênfase marxista no "poder" do Estado de direito moderno, decorre da avaliação de que tal posição subestima "seu funcionamento complexo", responsável por "[...] valores e práticas de civilização, cujo abandono não é menos que desastroso, como mostraram as experiências totalitárias do século passado" (FLORENZANO, 2007, p. 13-14). Em decorrência, ainda de acordo com 
Herculano Ricardo Campos | Záira Fátima de Rezende Gonzalez Leal | Marilda Gonçalves Dias Facci 두

Florenzano (2007), ao olhar para o aspecto "negativo" os marxistas deixaram de ver o lado positivo do Estado moderno, expresso nas características da civilização sob seus auspícios, notadamente tendo em vista a opressão vivida durante o feudalismo. Seu posicionamento é coerente com a compreensão que adota da estrutura do Estado, baseada em Max Weber, de acordo com quem se trata de uma "[...] entidade política, com uma 'Constituição' racionalmente redigida, um Direito racionalmente ordenado, e uma administração orientada por regras racionais, as leis, e administrado por funcionários especializados" (WEBER apud FLORENZANO, 2007, p. 11 ).

Embora se concorde que, no geral, o Estado de direito supera as experiências do mando monárquico-clerical vividas na ldade Média, também se entende que sua forma acabada, denominada Estado constitucionalista ou de direito, dadas as bases sobre as quais é fundado, é a expressão legal das forças que, na sociedade capitalista, dividida em classes, opera a dominação de uma classe sobre as demais. Nesse sentido, pois, ao Estado moderno se denomina Estado burguês, visto que essa classe foi estruturada para servir. Portanto, diferente da visão idealista de Weber - e de Florenzano - pondera-se que há limites e contradições em relação à pax civilizatória alcançada sob a égide do modo de produção capitalista e do Estado que the serve de suporte, cujas explicações se encontram nas razões históricas que presidiram a emergência do Estado como forma de organização da sociedade.

De acordo com Engels (2015), foi a desigual distribuição das riquezas, observada nas diferentes formas de organização social depois das sociedades ditas primitivas, organizadas segundo o modelo gentílico, que resultou na mudança de função do Estado,

[...] para cuja formação haviam progredido os grupos nativos de sociedades da mesma comunidade tribal, primeiramente, apenas em função da consecução de interesses comuns (por exemplo, a irrigação no Oriente) e da defesa contra ataques de fora [...] (ENGELS, 2015, p. 178).

Com base nessa contradição, que contribuir para aflorar as diferenças entre as classes, "A sociedade as subdivide em classes privilegiadas e desfavorecidas, exploradoras e exploradas, dominantes e dominadas". Nesse contexto, o Estado "[...] passa a ter, na mesma medida, a finalidade de assegurar, mediante a força, as condições de vida e o domínio da classe dominante 
Direito à Educação, formação do adolescente e adoecimento docente no Estado capitalista

contra a classe dominada" (ENGELS, 2015, p. 178). Nessa perspectiva, conclui Engels, em outro estudo, que,

Estado não é pois, de modo algum, um poder que se impôs à sociedade de fora para dentro; tampouco é "a realidade da idéia moral", nem "a imagem e a realidade da razão", como afirma Hegel. É antes um produto da sociedade, quando esta chega a um determinado grau de desenvolvimento; é a confissão de que essa sociedade se enredou numa irremediável contradição com ela própria e está dividida por antagonismos irreconciliáveis que não consegue conjurar (ENGELS, 1884, p. 61).

E acrescenta, reiterando que,

Como o Estado nasceu da necessidade de conter o antagonismo das classes, e como, ao mesmo tempo, nasceu em meio ao conflito delas, é, por regra geral, o Estado da classe mais poderosa, da classe economicamente dominante, classe que, por intermédio dele, se converte também em classe politicamente dominante e adquire novos meios para a repressão e exploração da classe oprimida (ENGELS, 1884, p. 62).

Assim, de modo significativamente distinto de Weber e Florenzano, como ressalta Lenine (1918, p. 4), "Para Marx, o Estado é um órgão de dominação de classe, um órgão de submissão de uma classe por outra; é a criação de uma "ordem" que legalize e consolide essa submissão, amortecendo a colisão das classes". Logo, o Estado é a síntese da estrutura jurídico-política, desenvolvida para manter a dominação da classe dominante perante as demais classes, de tal modo que seu poder é exercido de forma legal; uma estrutura que efetiva "[...] a defesa, pelo uso da força, das condições de vida e de governo da classe dominante frente à classe dominada" (ENGELS, 1884, p. 851.

Ao mesmo tempo que atende às necessidades de organização e regulamentação da sociedade marcada pela divisão do trabalho, o Estado também cumpre a função de dominação política: "[... ] só quando, juntamente com a função de tipo técnico-administrativo, nasce a função de dominação política é que se pode falar do aparecimento de um Estado propriamente dito" (HARNECKER, 1983, p. 1 17, grifos da autora). E, acrescente-se, a função de dominação política tem primazia sobre a técnica, de tal modo que funciona 
Herculano Ricardo Campos | Záira Fátima de Rezende Gonzalez Leal | Marilda Gonçalves Dias Facci

como orientadora desta, tirando da função técnico-administrativa qualquer resquício de neutralidade.

Assim, retomando a interlocução com Florenzano (2007), se depreende dos argumentos acima que a atribuição do Estado é só secundariamente civilizatória, antes se prestando, primariamente, a projeto de dominação. Os "valores e práticas de civilização", que Florenzano (2007) associa com o Estado de direito, ou moderno, embora se apresentem como objetivo de todos, na verdade, apenas a alguns são acessíveis, e ainda que constituam anseios de toda a sociedade, efetivamente representam conquista, apenas, de uma parte dela.

Enfatizar o Estado de direito enquanto expressão de certos valores e de certas práticas civilizatórias consideradas avançadas encobre as lutas surdas e suadas que têm lugar nos subterrâneos das relações sociais, entre as classes exploradas e as exploradoras, se valendo estas do poder do Estado. Negar ou desconsiderar a luta desigual, travada por parcela significativa da população para conquistar direitos e diminuir a exploração, e, ainda, apontar o Estado como bem de todos, trata-se de posição ingênua, idealista, que soma com a perspectiva da dominação. Nesse sentido, cabe observar o que afirma Maria de Fátima Rosar, sobre o refluxo da organização dos trabalhadores da educação nos anos 1990.

Esse movimento ascendente de contra-hegemonia teve curta duração, dado que as forças políticas que ocuparam a direção do país eram francamente conservadoras e impuseram aos movimentos dos educadores e aos movimentos sociais, de caráter classista, grandes perdas. Estas se iniciaram no Governo Collor de Melo e culminaram nos mandatos de Fernando Henrique Cardoso, direcionados ao cumprimento dos acordos de âmbito nacional e internacional celebrados entre a burguesia dominante no Brasil e nos demais países de capitalismo central, determinando os rumos da política econômica a ser implementada, com a finalidade precípua de subordinar as classes trabalhadoras dos países da América Latina, impondo-thes perdas de direitos e conquistas históricas, mediante reformas políticas, econômicas, educativas, trabalhistas e previdenciárias (ROSAR, 2012, p. 147).

A crítica fundamental dirigida ao modelo de organização política consolidada com a ascensão da burguesia ao poder, no contexto da Revolução 
Direito à Educação, formação do adolescente e adoecimento docente no Estado capitalista

Francesa, parte do questionamento dos princípios liberais que o fundam, notadamente da igualdade formal de todos. Ao tomar essa noção de liberdade como princípio, é negado que ela decorre das necessidades sociopolíticas, presentes na emergência do modo de produção capitalista, que, para se efetivar, requer indivíduos livres para negociar entre si a força de trabalho necessária ao desenvolvimento do sistema de produção. Em tal negociação, de um lado encontra-se uma pessoa que vende a única mercadoria de que dispõe, sua força de trabalho; de outro, se encontra aquele que a compra, para empregá-la na produção das mercadorias que serão postas no mercado e, assim, efetivar o capital (MARX, 2004).

Embora essa relação que se dá entre indivíduos livres requeira uma instituição que a regule, e nessa dimensão o Estado é importante e necessário, a respeito da mesma relação é negado que ela embute uma operação por meio da qual se dá a exploração da força de trabalho comprada, sobre a qual o comprador faz incidir mecanismos que a fazem produzir muito mais do que o montante investido na sua aquisição. Essa dimensão velada das relações sociais, fundante e essencial para o capitalismo, visto que somente a mercadoria força de trabalho humana agrega valor ao capital, é regulada somente

214 na medida da organização dos trabalhadores e sua reivindicação por direitos, configurando o que se denomina de questão social. Em tal dimensão, portanto, - Estado somente opera quando a força dos trabalhadores se faz sentir, e atua na perspectiva de amenizar o peso das reivindicações, de modo que se evidencia o caráter classista do Estado, notadamente a serviço do polo comprador de força de trabalho humana. Como afirma lamamoto,

desdobramento da questão social é também a questão da formação da classe operária e de sua entrada no cenário político, da necessidade de seu reconhecimento a nível de Estado e, portanto, da implementação de políticas que de alguma forma levem em consideração seus interesses (IAMAMOTO, 1983, p. 128).

É no bojo de tais considerações que se põe a discussão da educação como direito, passível de ser demandada enquanto políica do Estado, políitica pública, portanto suscetível aos interesses da classe que detém o poder do Estado. Na nossa sociedade, a efetivação do direito à educação é mediada pela correlação de forças que se observa entre o Estado burguês e as classes exploradas, de modo que sua efetividade jamais é um pressuposto, mas sim 
Herculano Ricardo Campos | Záira Fátima de Rezende Gonzalez Leal | Marilda Gonçalves Dias Facci

o resultado de tal embate; e, portanto, nunca uma concessão, mas sempre uma conquista, embora longe de ser todo o necessário para cumprir a função civilizadora que se pretende da educação. Assim, ao tratar do direito à educação, há que se atentar para o hiato entre o direito concebido e o direito efetivado, de modo que a contradição revelada na questão social precisa ser considerada para que o tema da educação como direito não seja, apenas, uma demanda vazia ou a expressão do lamento pelo direito não atendido.

A realidade brasileira pode ser tomada como um exemplo dos efeitos dessa contradição, bem como das lutas políticas que dela resultam, constituindo a dimensão da oferta pública de educação e os índices de matrícula, evasão e repetência a face cruel no nosso país do distanciamento entre o direito concebido e o direito efetivado, a expressão da conquista parcial de um direito tido como amplo. Da mesma forma, é no bojo dessa contradição que requer ser entendida a desumanização que se abate sobre professores e alunos. Enquanto os primeiros, devido às péssimas condições de trabalho que os alijam do processo de produção-socialização-apropriação do conhecimento, sentem deteriorar-se seu quadro de saúde e suas perspectivas de sucesso profissional, os adolescentes, por terem desconsideradas suas potencialidades, no processo de ensino-aprendizagem, não encontram sentido no que aprendem, e terminam se autoculpabilização por não se adaptarem a uma escola que não atende às suas necessidades. É o quadro relativo à situação de professores e alunos/adolescentes que será muito bem analisado a seguir.

\section{A formação do adolescente}

Entender a adolescência no período significativo do desenvolvimento humano pressupõe ter clareza das mudanças qualitativas vividas pelo indivíduo, bem como das novas estruturas que aparecem nessa fase. Formam-se os conceitos, que permitem a compreensão da realidade em suas múltiplas determinações e também o próprio mundo interno; formam-se a consciência, a autoconsciência e a concepção de mundo. Esses elementos evidenciam a dimensão das transformações pelas quais passa o adolescente, que vão muito além das transformações biológicas e corporais, preparando-o para a entrada na vida adulta e capacitando-o para exercer sua ação na realidade social, com base na comunidade onde está inserido. 
Essa perspectiva de compreensão da adolescência vem ganhando espaço na sociedade e na legislação voltada para esse segmento, como é o caso do Estatuto da Criança e do Adolescente - ECA -, aprovado na Constituição de 1988 e promulgado em 1990. Fruto dos movimentos que lutavam pelo fim da ditadura militar, pela redemocratização do Brasil e por políticas públicas de maior alcance social, o ECA representou a superação da Doutrina da Situação Irregular, marcada por visão parcializada e punitiva, e a adoção da Doutrina da Proteção Integral de Crianças e Adolescentes, no contexto da qual eles passavam a ser considerados sujeitos ativos, protagonistas da sua vida e da sua inserção social e, portanto, sujeitos de direitos, sem prejuízo da sua condição peculiar de desenvolvimento. De acordo com orientações emanadas do ECA, o 'protagonismo juvenil' configura a participação de crianças e adolescentes na luta pela garantia de seus direitos.

Não obstante somente haver se efetivado sob o ponto de vista legal no Estatuto, o discurso da participação dos jovens surgiu no Brasil com a Escola Nova, que a respeito da 'aprendizagem ativa' reconhecia a necessidade de participação dos alunos. Nos anos 1960, começam a se constituir os grêmios estudantis, com a organização dos alunos tanto em nível local, como em

216 nível estadual ou nacional. Tendo em vista o caráter explicitamente político dessa organização, sua força e seu crescimento estavam na dependência das conjunturas políticas, sendo mais solicitada e estimulada em alguns períodos e mais sufocada em outros, como na vigência da ditadura militar a partir de 1964. O movimento de reorganização democrática, a elaboração da nova Constituição Federal, reacendem a chama da participação popular, notadamente dos jovens. $\bigcirc$ campo educacional também ecoou a euforia pela nova realidade política do país, observando-se, na década de 1990, a emissão de diferentes documentos oficiais explicitando e valorizando a participação, propondo a descentralização e democratização da gestão escolar. Visava-se, com a criação de espaços atraentes e desafiadores aos jovens alunos, atingir resultados mais efetivos na escola.

A perspectiva do protagonismo juvenil requer, contudo, a adoção de alguns pressupostos, sem os quais o envolvimento dos adolescentes corre sério risco de se tornar mecânico, fruto apenas da obrigação, e, assim, pouco contribuindo para seu desenvolvimento. A participação desse segmento na realidade social e em sua comunidade, discutindo e atuando sobre as questões que o envolvem, requer que ele se aproprie do contexto no qual é chamado 
Herculano Ricardo Campos | Záira Fátima de Rezende Gonzalez Leal | Marilda Gonçalves Dias Facci

a participar, referenciado em uma concepção de mundo e em valores sobre os quais deve ter consciência. Tal perspectiva significativa deve encontrar, na escola, o contexto ideal para sua construção, de modo que é demandado dos educadores, como sinalizado acima e de antemão, a compreensão da adolescência e das transformações que se operam no indivíduo e em seu pensamento, como a formação e o desenvolvimento das funções psicológicas superiores, além da concepção biologizada e naturalizada, esvaziada de potencialidades, e que, atualmente, é hegemonicamente adotada.

Avalia-se que os estudos realizados com base nos pressupostos da Psicologia Histórico-Cultural permitem compreender a adolescência em seus aspectos mais significativos, trazendo, assim, a reflexão sobre as transformações cognitivas que podem ser fundamento para a sua ação participativa na sociedade e o seu posicionamento em relação a seus direitos e às políticas formuladas para seu grupo. Vygotski (1996), em sua época, já criticava as posições tradicionais da Psicologia em relação à adolescência, que, no seu entendimento, se restringiam a descrever comportamentos e a estudar o conjunto de indícios exteriores que diferenciavam os diversos períodos de desenvolvimento, em lugar de estudar o que se encontra por detrás desses indícios, os elementos psicológicos constituídos histórica e culturalmente.

A adolescência vem sendo compreendida e difundida como um período difícil, cheio de conflitos e instabilidade, com crise de identidade e falta de clareza sobre seu próprio posicionamento diante da vida. Essa situação impeliria o adolescente para comportamentos de rebeldia, transgressão, negação e não aceitação das regras estabelecidas, e de oposição ao controle dos adultos. Concebida a adolescência desta forma, torna-se difícil pensar na participação do adolescente na sua comunidade e na luta pela formulação de políticas que atendam às suas necessidades sociais.

Segundo Tolstii (1989), a interpretação da adolescência como idade 'difícil' é um dos prejuízos que proliferam na Psicologia. Para o autor, embora esse período seja, muitas vezes, denominado de 'difícil', 'crítico', 'turbulento', refletindo a complexidade dos processos que se operam nessa idade, o conteúdo fundamental de todos os aspectos do desenvolvimento, nessa etapa, é a estruturação de formações qualitativamente novas. Formam-se elementos do adulto, resultantes da transformação do organismo, da formação da autoconsciência, do tipo de relações estabelecidas com os companheiros e com os adultos, dos novos modos de interação social, dos novos interesses, da 
Direito à Educação, formação do adolescente e adoecimento docente no Estado capitalista

atividade cognoscitiva, das instâncias ético-morais que realizam a mediação com o meio circundante (DRAGUNOVA, 1985).

Altera-se o lugar que o adolescente ocupa, com participação mais efetiva em atividades que estão mais próximas do adulto, devido às suas novas capacidades físicas, conhecimentos e habilidades. Do ponto de vista da consciência, a transição para a adolescência é marcada pelo crescimento de uma atividade crítica em face das exigências, do comportamento e das qualidades pessoais dos adultos, pelo surgimento de novos interesses, verdadeiramente teóricos, e da necessidade de conhecer a realidade que o cerca e o que é conhecido sobre a mesma (LEONTIEV, 2001).

Da mesma forma, cresce o interesse cognoscitivo em relação aos princípios de funcionamento do mundo, das leis universais da natureza e da existência humana, requerendo do adolescente a necessidade de generalizar as informações e dados acumulados até então; assume lugar central a solução de problemas sociais e morais, agrupados em torno da formulação do sentido da vida. $\bigcirc$ adolescente busca "[...] encher sua própria vida de um conteúdo socialmente significativo. Precisamente por isso o problema do sentido da vida adquire um tom tão íntimo e um valor emocional e não há para ele 218 uma resposta pronta" (KON, 1985, p. 202). Seu desenvolvimento psíquico e maior capacidade de abstração the permitem compreender melhor a realidade, favorecendo uma maior inserção no meio cultural, o que torna possível uma participação e intervenção consciente mais efetivos em sua comunidade e na realidade social, buscando compreender e lutar por seus direitos, de forma plenamente participativa.

Por outro lado, o desenvolvimento cognitivo do adolescente, do qual depende sua participação social, está na dependência da educação escolar. Elkonin (1987) destaca a adolescência pelas mudanças decorrentes da forma como as relações mediatizadas com o mundo circundante se refletem no psiquismo do indivíduo, de modo que a educação se apresenta como significativa na sua formação. No Brasil, o esvaziamento e empobrecimento da educação escolar, permeada pela concepção do 'aprender a aprender', voltada, sobretudo, para a socialização dos alunos e marcada por conteúdos superficialmente trabalhados, tem proporcionado resultados pouco efetivos em termos do desenvolvimento dos adolescentes, da formação do pensamento teórico que thes permitiria compreender a realidade em sua essência. Em decorrência, 
Herculano Ricardo Campos | Záira Fátima de Rezende Gonzalez Leal | Marilda Gonçalves Dias Facci

muito mais dificultada fica sua participação política e social, muito mais difícil é dar conta do protagonismo juvenil.

Essa forma de compreender a adolescência, em face da qual se organiza o processo educativo, revela uma particularidade da contradição entre o que se propõe como direito à educação e as condições efetivamente postas para sua consecução. Em que pese em geral as políticas educacionais fazerem referência à intenção de formar um aluno crítico, consciente da sua realidade e apto para nela atuar de modo construtivo, para assim exercer ativamente sua cidadania, o que se encontra são escolas esvaziadas de conteúdos significativos para aqueles que as frequentam. As instituições escolares apenas acolhem os alunos, de modo que os conhecimentos ofertados minimamente contribuem para o desenvolvimento cognitivo e a formação de indivíduoscríticos e conscientes. $\bigcirc$ que se observa é a busca por alunos adaptados e passivos - para tanto se valendo, inclusive, da nefasta estratégia da medicalização.

Nessas condições, considerar crianças e adolescentes como sujeitos de direitos, bem como a educação como Direito Humano Fundamental, ainda não passa de uma formulação legal, uma intenção contida na lei, cujo efeito nefasto incide sobre os estudantes e também sobre os professores. Em que pese a legislação, ideologicamente, defender uma educação de qualidade e o acesso dos alunos ao conhecimento, muito pouco é feito para aproveitar as potencialidades desses jovens, bem como muito menos é disponibilizado para que os professores possam ter condições objetivas de desenvolver uma educação significativa.

Assim, o sistema educacional, premido pelas peculiaridades de uma sociedade capitalista, marcada pelo distanciamento entre os planos do discurso oficial e o da realidade, os planos da política pública como direito e o da ação efetiva com vistas a implementá-lo, produz alunos que, aparentemente, estão desinteressados em aprender, e professores que adoecem em face dos desafios que thes são postos pelos educandos, mas que não encontram condições de atender, devido ao descaso com a educação e com a sua função de trabalhador, conforme será visto a seguir. 


\section{O sistema de ensino e o adoecimento do professor}

nível de adoecimento dos professores tem sido atestado por várias pesquisas, tais como Codo (1 999), Assunção e Oliveira (2009), Mosquera e Stobäus (1996) e Zaragoza (1 999). Depressão, Síndrome do Pânico, Malestar docente, Síndrome de Burnout, entre outros, são diagnósticos elencados na literatura como problemas enfrentados pelo professor.

As políticas educacionais, propondo uma educação baseada na Pedagogia das Competências, no Construtivismo e na Teoria do Professor Reflexivo, têm, nos últimos anos, esvaziado o trabalho do professor, conforme afirma Facci (2004). Essas tendências pedagógicas, nas quais o aluno torna-se o centro do processo pedagógico - desconsiderado o papel do professor e do conteúdo -, focadas mais na experimentação e na experiência do aluno e mesmo do professor, em detrimento de uma formação fundamentada no conhecimento teórico, têm contribuído para que o professor seja, correntemente, colocado à margem do processo educativo, conforme propõe a autora, secundarizado no processo ensino e aprendizagem. A essência do trabalho do professor - que seria a transmissão e apropriação dos conhecimentos pro-

220 duzidos nas várias ciências, no processo histórico, conforme propõe Saviani (2003) - acaba sendo perdida, sendo submetido a um processo de alienação.

$\bigcirc$ direito e dever de ensinar acabam sendo deixados de lado, na luta árdua do dia a dia, para o enfrentamento do dilema de ensinar em uma sociedade de classes, que pouco interesse tem em que a classe trabalhadora tenha acesso ao conhecimento mais elaborado. A meta é garantir o direito de ter acesso ao mínimo conhecimento científico; garantir somente o necessário para manter o sistema de produção vigente e assegurar a garantia da qualificação para o trabalho, apregoada pela Constituição de 1988.

A escola vem assumindo diversas funções sociais, uma vez que, como afirma Saviani (2003), está atrelada à forma como os homens se organizam para transformar a realidade, no processo histórico. Não existe uma escola neutra, ela sempre está vinculada à ideologia que se pretende disseminar; está condicionada à materialidade da sociedade. O Estado classista dita as normas do funcionamento da escola, e, como se disse anteriormente, quer perpetuar a divisão entre aqueles que têm os meios de produção e aqueles que têm a força de trabalho. No entanto, contraditoriamente, ela pode transformar a consciência dos alunos e, nesse sentido, teria como objetivo socializar os 
Herculano Ricardo Campos | Záira Fátima de Rezende Gonzalez Leal | Marilda Gonçalves Dias Facci

conhecimentos produzidos pela humanidade, de forma a tornar individualizados estes conhecimentos, conforme menciona Saviani (2003). No caso do Ensino Fundamental, nos primeiros anos, ela teria como função ensinar a ler, escrever, a dominar os sistemas de numeração e operação com a matemática, assim como iniciar o aluno na compreensão do mundo em nível da História e da Ciência (SAVIANI, 2003). No entanto, considerando o elevando índice de fracasso escolar - desafio historicamente posto para a educação brasileira - o direito à educação está longe de ser efetivado.

Nesse processo ensino-aprendizagem, cabe à escola, de acordo com Vigotski (2000), ao ensinar os conhecimentos científicos, provocar o desenvolvimento psicológico dos alunos. $\bigcirc$ autor russo parte da premissa de que aprendizagem promove desenvolvimento das funções psicológicas superiores, e o professor, ao transmitir os conteúdos curriculares, além de estar instrumentalizando o aluno para conhecer a realidade, também está provocando a formação social da mente.

A formação das funções psicológicas superiores, tais como a memória, a atenção, a abstração, entre outras, influencia a forma como o indivíduo se relaciona com a realidade e a constituição da sua personalidade (VYGOTSKI, 1996), que é constituída pelas relações sociais de produção, no sentido de que "[...] cada pessoa é em maior ou menor grau o modelo da sociedade, ou melhor, da classe a que pertence, já que nela se reflete a totalidade das relações sociais" (VIGOTSKI, 1996, p. 368). Esse entendimento da formação do individuo pode guiar a compreensão que se tem sobre o sofrimento/adoecimento do professor.

Pesquisa realizada por Santos e Facci (2012) na base de dados "Scielo" durante o mês de março de 2012, com o objetivo de analisar como o adoecimento e sofrimento do professor estão sendo compreendidos na produção científica, identificou somente 14 trabalhos que enfatizavam o adoecimento psíquico. Doze deles (85,7\%) relacionam o adoecimento do professor com as condições do local de trabalho onde estão inseridos e o modo como este está organizado. Em sete dos 14 trabalhos, ou seja, em 50\% dos artigos pesquisados, identificou-se a tematização do adoecimento psíquico do professor abordando a Síndrome de Burnout. Esse resultado tanto foi observado em estudos elaborados com base em pesquisas bibliográficas, como em estudos de campo e pesquisa experimental. 
Direito à Educação, formação do adolescente e adoecimento docente no Estado capitalista

De forma geral, segundo Santos e Facci (2012), os determinantes que contribuem para o adoecimento do professor estão relacionados: à falta de reconhecimento da sua função; à falta de respeito dos alunos, dos governantes e sociedade em geral; a baixos salários; a diminuição dos espaços de discussão coletiva; a tripla jornada; a sobrecarga de trabalho; a baixa participação direta na gestão e planejamento do trabalho; a culpabilização pelos resultados negativos dos alunos; a invasão do espaço domiciliar; a inclusão de crianças com necessidades educacionais especiais em classes de ensino regular, entre outros. Pode- se considerar, com esses dados, que o direito de constituição do gênero humano, por meio da atividade profissional, ainda está longe de ocorrer, o que pode causar o adoecimento.

Análise empreendida por Assunção e Oliveira (2009) revela que a intensificação do trabalho nas escolas, fundamentando-se na implantação de reformas educacionais, desde a década de 1990, tem contribuído, também, para o adoecimento do professor, para essa sensação de mal-estar diante das tarefas cotidianas na sala de aula, e, ainda. para essa sensação de não estar conseguindo cumprir com a função social da escola.

Constata-se que o significado social da escola nem sempre está rela222 cionado ao sentido que o professor atribui à sua prática pedagógica. Leontiev (1978, p. 95) afirma que o significado (ou significação) social se refere "[...] ao mundo dos fenômenos objetivamente históricos [...]", que são assimilados de geração a geração. No caso da escola, seu significado é, conforme Saviani (2003), socializar os conhecimentos produzidos pelos homens. $\bigcirc$ sentido, para Leontiev (1978, p. 98), "[...] é criado pela relação objetiva que se reflete no cérebro do homem, entre aquilo que o incita a agir e aquilo para o qual a sua ação se orienta como resultado imediato". O sentido do trabalho do professor, muitas vezes, tem-se constituído como uma atividade que possibilita ter recursos financeiros - o salário - para pagar as suas despesas, e está muito longe de se vincular ao significado social do ato de ensinar.

Leontiev (1978) compreende que, na sociedade capitalista, ocorre um processo de alienação por meio do qual se opera uma cisão entre o sentido pessoal e o significado social das atividades. Silva (2006) considera que os professores estão perdendo o sentido do trabalho e estão vivenciando um sentimento de impotência ante a tentativa de torná-lo mais significativo. $\bigcirc$ trabalho não material realizado pelo professor - considerando que esse trabalha com as ideias, com os conhecimentos de várias ciências - tem sido permeado 
Herculano Ricardo Campos | Záira Fátima de Rezende Gonzalez Leal | Marilda Gonçalves Dias Facci

pelas mesmas características do trabalho de forma geral: pelo estranhamento em relação ao próprio trabalho e a si mesmo. Em pesquisa realizada com professores que estavam em processo de adoecimento, Silva (2006) concluiu que as condições precárias de trabalho e a falta de perspectivas profissionais têm contribuído para o abandono da profissão. $\bigcirc$ profissional sente um distanciamento da atividade docente, e acaba não se envolvendo com o trabalho, o que está relacionado com a reestruturação produtiva e as reformas neoliberais.

No contexto da massificação do professor, na condição de trabalhador, por influência de preceitos neoliberais, da reestruturação produtiva, das reformas que vêm ocorrendo na educação, observa Santos (2014) que eles são cobrados a responder questões cujas respostas estão muito além da sua formação. Oliveira (2004) fortalece o segmento de estudiosos que relacionam o adoecimento do professor com as condições de trabalho, e assinala o seguinte:

que temos observado em nossas pesquisas é que os trabalhadores docentes se sentem obrigados a responder às novas exigências pedagógicas e administrativas, contudo expressam sensação de insegurança e desamparo tanto do ponto de vista objetivo - faltam- Ihes condições de trabalho adequadas - quanto do ponto de vista subjetivo (OLIVEIRA, 2004, p. 140).

Em face do processo de alienação, os professores deixam de ver sentido no que estão fazendo e, na maioria das vezes, não conseguem encontrar motivo para ensinar. Tal ruptura entre significado e sentido, do ponto de vista deste estudo, pode contribuir para o sofrimento e adoecimento do professor. A precarização do trabalho que se observa em várias profissões atinge também os professores, que estão inseridos nesse contraditório espaço de direitos, apresentados e pouco usufruídos.

Os professores, de forma geral, querem ensinar; os alunos querem aprender, mas condições objetivas desfavoráveis - tais como pouco investimento na educação e na formação de professores, falta de estrutura física adequada para o processo de escolarização, baixos salários, entre outras, - impedem que o processo de socialização e apropriação do conhecimento seja realizado com êxito, causando sofrimento em professores e alunos. Nem sempre ocorre a apropriação dos conhecimentos científicos pelos alunos. Aquilo que deveria ser garantido em termos do direito humano à educação, 
Direito à Educação, formação do adolescente e adoecimento docente no Estado capitalista

não ocorre no espaço escolar. No Relatório Nacional Pisa $2012^{2}$ (BRASIL, 2012 ) consta que 37,4\% dos estudantes brasileiros, quando interrogados se já tiveram alguma reprovação, afirmaram ter repetido uma ou mais vezes. A tabela do documento demonstra que os países sul-americanos têm uma taxa de repetência mais elevada que a de outros países e que o Brasil, entre todos estes, tem o percentual mais alto.

Agregado a esse nível de reprovação, é patente na sociedade a desvalorização da escola e, consequentemente, do trabalho do professor, ou mesmo um esvaziamento no seu trabalho, conforme mencionado anteriormente. Vive-se a desvalorização da teoria, daquilo que deveria instrumentalizar o professor em sua prática profissional, e a cada ano que passa defronta-se com número mais elevado de profissionais afastados da escola por problemas de saúde.

\section{Considerações finais}

Neste artigo discutiram-se os efeitos do hiato observado entre o direito 224 universal à educação, como previsto na Constituição de 1988 e em outras Cartas, desde o período imperial, no Brasil. Para tanto, partiu-se da reflexão sobre as características do Estado e sua função de controle social a serviço de uma classe, particularmente mostrando como isso se dá sob o capitalismo, em que é ensejada a questão social. Revelaram-se, em seguida, os efeitos desse distanciamento entre a legislação e a realidade educacional no que concerne à formação de adolescentes e à prática profissional do professor.

Apontou-se que adotar o ideário liberal e a perspectiva positivista como diretriz para compreender, por exemplo, os fatos humanos e os aspectos da educação aqui tratados, o adoecimento do professor e o inconformismo dos adolescentes aparecem como problemas individuais de personalidade, afeitos a aspectos subjetivos da vida deles. Em decorrência, nada mais natural que sejam culpabilizados, uns por não serem mais criativos em sala de aula, por não estarem mais próximos dos alunos, por não compreenderem as 'crises da adolescência'; e outros, por serem desatentos, por estarem vivendo a 'idade da crise', por terem desenvolvido transtorno desafiador opositor. Esse olhar, preso à aparência do fenômeno educacional, faz desaparecer a discussão a respeito do direito de ensinar e de aprender, apregoado em vários 
Herculano Ricardo Campos | Záira Fátima de Rezende Gonzalez Leal | Marilda Gonçalves Dias Facci

documentos nacionais e internacionais, bem como as razões que impedem a efetivação do direito. Em outras palavras: direito anunciado, mas pouco garantido diante da precarização das condições objetivas das escolas e do pouco investimento financeiro à educação.

Observou-se que a legislação sobre o direito à educação no Brasil remonta de longa data, desde a Constituição Imperial de 1824 e, mais atualmente, na Constituição Federal de 1988 e na Lei de Diretrizes e Bases da Educação Nacional n 9394, de 20 de dezembro de 1996. Não obstante, como afirma Dias (2007), é importante entender as determinações sociais e políticas que, historicamente, vêm imprimindo contorno às formulações institucionais. Nesse sentido, tendo em vista a Carta de 1988 e a LDB, tais leis refletem discussões originadas ainda nos anos 1950 e 1960, sobre a relação entre educação e desenvolvimento, em que emerge a defesa da escola pública, ou seja, da educação para todos, obrigatória e gratuita, visando ao pleno desenvolvimento da pessoa, à constituição da cidadania e qualificação para o trabalho (BRASIL, 1988). Mas, como apontado no presente artigo, pertinente aos estudantes, nem o "pleno desenvolvimento da pessoa", ou "seu preparo para o exercício da cidadania" e mesmo "sua qualificação para o trabalho" vêm sendo efetivados pelo atual sistema educacional. E, sob o ponto de vista dos professores, as mesmas limitações do sistema têm incidido de forma comprometedora sobre sua saúde física e psicológica, impedindo-os de ensinar.

A história relativa às negociações sobre o texto da LDB aponta que, não obstante a concepção ampla do direito à educação para todos, independente de possível deficiência e do grau da mesma, e da classe social a que o indivíduo pertence, como se encontra na Constituição, foi marcante a contradição entre os interesses públicos e privados. Como os empresários pleiteavam espaços na estrutura educacional que pudessem explorar, sem a concorrência do Estado, a este coube, apenas, a oferta do Ensino Fundamental. Ainda que, atualmente, essa situação tenha se modificado, ela é exemplo do quanto a educação é campo de disputa e do quanto o resultado de tal disputa depende das forças que dela participam. Ou seja, exemplo de que o direito, em si, não garante aquilo que apregoa.

Em outras palavras, como o Estado não é um ente subjetivo, mas efetivamente constituído de pessoas concretas, com inserção concreta na estratificação social, essas pessoas que representam no Estado os interesses de seus 
grupos sociais procuram fazer com que tais interesses particulares sejam adotados coletivamente, e nesse contexto a forçado capital é fundamental para a garantia do sucesso de tais interesses. Em decorrência, o direito de todos se apresenta sempre como uma meta a ser conquistada. No discurso, a escola é para todos, mas, no cotidiano, o acesso ao conhecimento ainda acaba sendo destinado a uma parcela específica da população, de modo que adolescentes podem ficar sem acesso a uma escola que considere suas peculiaridades e potencialidades, e os professores podem ser levados a adoecer devido à falta de condições favoráveis para ensinar.

Se o direito à educação é considerado fundamental, a realidade, atualmente, vivenciada por professores e alunos/adolescentes revela a necessidade da luta constante pela efetividade desse direito. Nessa luta, é importante ter claro os interesses de classe que caracterizam a forma de ser do Estado, bem como a necessidade de os estudantes e trabalhadores da educação buscarem os apoios necessários para fazer valer suas demandas diante aos interesses privados, privilegiados pelo Estado.

\section{Notas}

1 Artigo fruto de trabalho apresentado no VI CIPSI - Congresso Internacional de Psicologia da Universidade Estadual de Maringá (UEM), - XVI Semana de Psicologia da UEM e VIII Seminário de Pesquisa do Programa de Pós-Graduação em Psicologia da UEM, realizado em maio de 2015, através do Centro de Ciências Humanas, Letras e Artes e do Departamento de Psicologia da UEM.

2 Programa Internacional de Avaliação de Estudantes (Pisa) é uma avaliação comparada, cuja principal finalidade é produzir indicadores que contribuam para a discussão da qualidade da educação nos países participantes, de modo a subsidiar políticas de melhoria do ensino básico. As avaliações do Pisa acontecem a cada três anos e abrangem três áreas do conhecimento Leitura, Matemática e Ciências (BRASIL, 2012).

\section{Referências}

ASSUNÇÃO, Ada Ávila; OLIVEIRA, Dalila Alves. Intensificação do trabalho e saúde dos professores. Educação \& Sociedade, Campinas, v. 30, n. 107, p. 349-372, 2009.

BRASIL. Constituição Política do Império do Brasil (1824). Disponível em: http://www. monarquia.org.br/pdfs/constituicaodoimperio.pdf. Acesso em: 29 mar. 2015. 
Constituição da República dos Estados Unidos do Brasil (1934). Disponível em: http://www.planalto.gov.br/ccivil_03/Constituicao/Constituicao34.htm Acesso em: $1^{\circ}$ maio 2016.

. Constituição dos Estados Unidos do Brasil (1946). Disponível em: http://www. planalto.gov.br/ccivil_03/Constituicao/Constituicao46.htm Acesso em: $1^{\circ}$ maio 2016.

. Constituição da República Federativa do Brasil. Senado Federal. Brasília: Centro Gráfico, 1988.

Instituto Nacional de Estudos e Pesquisas Educacionais Anísio Teixeira (Inep). Relatório Nacional Pisa 2012 - Resultados Brasileiros. Brasília, 2012. Disponível em: http://download.inep.gov.br/acoes_internacionais/pisa/resultados/2014/relatorio_ nacional_pisa_2012_resultados_brasileiros.pdf Acesso em: 26 abr. 2016.

Instituto Nacional de Estudos e Pesquisas Educacionais Anísio Teixeira (Inep). IDEB: resultados e metas. Brasília, 2015. Disponível em: http://ideb.inep.gov.br/resultado/resultado/resultadoBrasil.seam?cid=1779426. Acesso em: 26 abr. 2015

CODO, Wanderley (Org.). Educação: carinho e trabalho - Burnout, a síndrome da desistência do educador, que pode levar à falência da educação. Rio de Janeiro: Vozes, 1999.

FRANÇA. Declaração dos Direitos do Homem e do Cidadão (1789). Disponível em: http:// www.dhnet.org.br/direitos/anthist/dec 1793.htm Acesso em: 29 mar. 2015.

PLATAFORMA DHESC-Brasil. Plataforma Brasileira de Direitos Humanos Econômicos, Sociais e Culturais. Relatório Brasileiro sobre Direitos Humanos Econômicos, Sociais e Culturais. 2003. Disponível em: www.dhescbrasil.org.br. Acesso em: 29 mar. 2015.

DIAS, Adelaide Alves. Da educação como direito humano aos direitos humanos como princípio educativo. In: SILVEIRA, Rosa Maria Godoy; DIAS, Adelaide Alves; FEITOSA, Maria Luiza Pereira de Alencar Mayer; ZENAIDE, Maria de Nazaré Tavares (Org.). Educação em direitos humanos: fundamentos teórico-metodológicos. João Pessoa: Editora Universitária UFPB, 2007. Disponível em: http://www.dhnet.org.br/dados/livros/edh/br/fundamentos/26_cap_3_artigo_04.pdf. Acesso em: 22 out. 2015.

DRAGUNOVA, Tatiana Vasílievna. Características psicológicas del adolescente. In: PETROVSKI, ARTUR (Org.). Psicologia evolutiva y pedagogica. Moscou: Progresso, 1985.

ELKONIN, Daniil Borisovich. Sobre el problema de la periodización del desarrollo psíquico en la infancia. In: DAVIDOV, Vasili; SHUARE, Marta (Org.) La psicologia evolutiva y pedagógica en la URSS (Antologia). Moscou: Editorial Progresso, 1987. 
Direito à Educação, formação do adolescente e adoecimento docente no Estado capitalista

ENGELS, Friedrich. A origem da família, da propriedade privada e do Estado. Zurique. 1884. Disponível em: http://www.dhnet.org.br/direitos/anthist/marcos/hdh_engels_origem_propriedade_privada_estado.pdf. Acesso em: 31 ago. 2015.

Anti-dühring: a revolução da ciência segundo o senhor Eugen Dühring. Tradução Nélio Schneider. São Paulo: Boitempo, 2015.

FACCl, Marilda Gonçalves Dias. Valorização ou esvaziamento do trabalho do professor? Um estudo crítico-comparativo entre a teoria do professor reflexivo, o construtivismo e a escola de Vigotski. Campinas: Autores Associados, 2004.

FLORENZANO, Modesto. Sobre as origens e o desenvolvimento do Estado moderno no ocidente. Lua Nova, São Paulo, n. 71, p. 11-39, maio/ago. 2007.

GRACIANO, Mariângela. A educação como direito humano: a escola na prisão. 2005. 154f. Dissertação (Mestrado em Educação) - Programa de Pós-Graduação em Educação, Universidade de São Paulo, São Paulo, 2005.

HARNECKER, Marta. Os conceitos elementares do materialismo histórico. São Paulo: Global, 1983.

IAMAMOTO, Marilda Vilella e CARVALHO, Raul de. Relações sociais e serviço social no

228 Brasil: esboço de uma interpretação histórico-metodológica. São Paulo: Cortez; CELATS, 1983.

KON, Igor Semyonovich. Psicologia de La primera juventud. In: PETROVSKI, Artur. Psicologia evolutiva y pedagogica. Moscou: Editorial Progresso. 1985.

LENINE, Vladimirllitch. O Estado e a revolução. Moscou. 1918. Disponível em: http://pcb. org.br/portal/docs/oestadoearevolucao.pdf. Acesso em: 21 out. 2015.

LEONTIEV, Alexis Nikolaevich. O desenvolvimento do psiquismo. Lisboa: Livros Horizonte, 1978.

Uma contribuição à teoria do desenvolvimento da psique infantil. In: VIGOTSKII, Lev Semenovich; LURIA, Alexander Romanovich; LEONTIEV, Alexis Nikolaevich. Linguagem, desenvolvimento e aprendizagem. São Paulo: ĺcone, 2001.

MARX, Karl. O capital: crítica da economia política. Rio de Janeiro: Civilização Brasileira, 2004.

MOSQUERA, Juan José Mouriño; STOBÄUS, Claus Dieter. $\bigcirc$ mal-estar na docência: causas e conseqüências. Educação, Porto Alegre, v. 19, n. 31 , p. 139-146, 1996. 
OLIVEIRA, Dalila Andrade. A reestruturação do trabalho docente: precarização e flexibilização. Educação \& Sociedade, Campinas, v. 25, n. 89, p. 11 27-1 144, set./dez. 2004.

ROSAR, Maria de Fátima Felix. Educação e movimentos sociais: avanços e recuos entre o século XX e o século XXI. Educação em Revista, Marília, v. 12, n. 2, p. 145-162, jul./dez. 2012

SANTOS, Diego Augusto dos. Contribuições da psicologia histórico-cultural para a compressão do adoecimento e sofrimento psíquico de professores. 2014 . 195f. Dissertação (Mestrado em Psicologia) - Programa de Pós-Graduação em Psicologia, Universidade Estadual de Maringá, Maringá, 2014.

SANTOS, Diego Augusto dos; FACCl, Marilda Gonçalves Dias. $\bigcirc$ adoecimento e sofrimento psíquico de professores: difusão em produções científicas. In: CONGRESSO INTERNACIONAL DE PSICOLOGIA, 5; 2012 , Maringá. Anais... Maringá: Universidade Estadual de Maringá, 2012.

SAVIANI, Dermeval. Pedagogia histórico-crítica: primeiras aproximações. Campinas: Cortez/Autores Associados, 2003.

SILVA, Nilma Renildes da. Relações sociais para superação da violência escolar e processos formativos de professores. 2006. 298f. Tese (Doutorado em Educação) - Programa de Estudos Pós-Graduados em Educação, Pontifícia Universidade Católica de São Paulo, São Paulo, 2006.

TOLSTI, Alexandr. El hombre y laedad. Moscou: Editorial Progresso, 1989.

VIÉGAS, Lygia de Sousa; ASBAHR, Flávia da Silva Ferreira; ANGELUCCl, Carla Biancha. Apresentação. In: VIÉGAS, Lygia de Sousa; ANGELUCCl, Carla Biancha (Org.). Políticas públicas em educação: uma análise crítica a partir da psicologia escolar. São Paulo: Casa do Psicólogo, 2006.

VIGOTSKI, Lev Semenovich. Teoria e método em psicologia. São Paulo: Martins Fontes, 1996.

A construção do pensamento e da linguagem. São Paulo: Martins Fontes, 2000.

Obras escogidas III. Madrid: Centro de Publicacionesdel M.E.C. y Visor Distribuciones, 1995. 1996.

Psicologia del Adolescente. In: Obras escogidas IV. Madrid: Visor Distribuciones, 
ZARAGOZA, José Manuel Esteve. O mal-estar docente: a sala de aula e a saúde dos professores. Bauru: EDUSC, 1999.

Prof. Dr. Herculano Ricardo Campos Universidade Federal do Rio Grande do Norte Departamento de Psicologia Programa de Pós-Graduação em Psicologia Núcleo de Estudos em Psicologia Histórico Cultural

E-mail | herculanorcampos@gmail.com

Profa. Dra. Záira Fátima de Rezende Gonzalez Leal Universidade Estadual de Maringá Programa de Pós-Graduação em Psicologia Grupo de Pesquisa Psicologia Histórico-Cultural e Educação E-mail | zairagleal@gmail.com

Profa. Dra. Marilda Gonçalves Dias Facci Universidade Estadual de Maringá Programa de Pós-Graduação em Psicologia Grupo de Pesquisa em Processos Educativos e Práticas Sociais E-mail | marildafacci@gmail.com

Recebido 19 jan. 2016 Aceito 12 abr. 2016 